\title{
Mapping Organizational Culture Schemas Based on Correlational Class Analysis: A Tutorial
}

\section{Mapeando Esquemas da Cultura Organizacional por Meio da Análise de Classes Correlacionais: Um Tutorial}

\author{
Luciano Rossoni ${ }^{1}$ c \\ Clayton Pereira Gonçalves ${ }^{10}$ \\ Mônica Pereira da Silva ${ }^{1}$ [0 \\ Alex Ferreira Gonçalves ${ }^{10}$
}

\section{ABSTRACT}

Context: organizational culture tends to be investigated based on organizational consensus degree, even when it is seen as shared meanings. However, sharing meanings does not imply having the same opinions. On the contrary, there may be agreement on which cultural elements are relevant, even when opinions differ from each other, a fact that enables individuals to share cultural schemas, although they disagree with each other's answers. Objective: we aim to use a scale of organizational values adapted to the Brazilian context to map cultural schemas based on a survey conducted with 207 workers from different companies. Method: recent advancements in the cultural cognition field have enabled the present tutorial article to map organizational culture schemas based on correlational class analysis. This method divides the sample into schematic classes by listing respondents based on the linear dependence between answers given to a questionnaire, rather than on agreement between respondents. Results: two different schematic classes (reactive and resilient) that condition the effect of attitudes and organizational structure on employee appreciation and satisfaction. Conclusions: besides providing a tutorial on how to use the investigated technique, the study points out its relevance for organizational culture field.

Keywords: correlational class analysis; belief systems; shared meanings; organizational culture; cultural schemas.

1. Universidade do Grande Rio, Programa de Pós-Graduação em Administração, Rio de Janeiro, RJ, Brazil.

Cite as: Rossoni, L., Gonçalves, C. P., Silva, M. P. da., \& Gonçalves, A. F. (2021). Mapping organizational culture schemas based on correlational class analysis: A tutorial. Revista de Administração Contemporânea, 25(1), e200096. https://doi.org/10.1590/1982-7849rac2021200096

\section{RESUMO}

Contexto: a cultura organizacional, mesmo quando vista como significados compartilhados, tende a ser investigada a partir do grau de consenso organizacional. Todavia, compartilhar significados não implica dizer que as opinióes são as mesmas. Pelo contrário, pode haver concordância em quais elementos culturais são relevantes, mesmo que as opinióes divirjam. Isso remete à possibilidade de indivíduos compartilharem esquemas culturais mesmo que discordem das respostas. Objetivo: nosso objetivo é mapear os esquemas culturais compartilhados por meio de uma escala de valores organizacionais adaptada ao contexto brasileiro, a partir de uma survey com 207 trabalhadores de diferentes companhias. Método: avanços recentes no campo da cognição cultural permitiram, neste artigo tutorial, mapear os esquemas da cultura organizacional por meio da análise de classes correlacionais. Tal método divide a amostra em classes esquemáticas, elencando os respondentes por meio do grau de dependência linear entre respostas em um questionário, e não pela concordância. Resultados: os resultados apontam para duas classes distintas de esquemas (reativos e resilientes), que condicionam o efeito de atitudes e da estrutura organizacional na valorização e satisfação dos funcionários. Conclusóes: além de fornecermos um tutorial de uso da técnica, nós apontamos sua relevância para os estudos sobre cultura organizacional.

Palavras-chave: análise de classes correlacionais; sistemas de crenças; significados compartilhados; valores organizacionais; esquemas culturais.

JEL Code: A14, Z1, A23 Editor-in-chief: Wesley Mendes-Da-Silva (Fundação Getulio Vargas, EAESP, Brazil) (1) Associate Editor: Henrique Castro Martins (PUC Rio, IAG, Brazil) Reviewers: Charles Kirschbaum (Instituto de Ensino e Pesquisa (INSPER), Brazil) Christine da Silva Schröeder (Universidade Federal do Rio Grande do Sul, EA, Brazil) (e)

\begin{tabular}{|c|c|c|c|c|c|c|c|c|}
\hline 1 & 2 & 3 & 4 & 5 & 6 & 7 & 8 & 9 \\
\hline$x$ & $\stackrel{9}{2}$ & (x) & (x) & (x) & $\stackrel{9}{2}$ & (x) & & \\
\hline
\end{tabular}




\section{INTRODUCTION}

Exploring the concept of organizational culture based on shared meaning schemas has been used as a relevant line of investigation in organizational studies (MacQueen, 2020; Oberg, Korff, \& Powell, 2017; Reisyan, 2016; Smircich, 1983). It happens because organizational culture schemas can affect organizations' behavior since they are shared mental representations of what organizations mean in terms of beliefs, values, and attitudes (Harris, 1994; Langfield-Smith, 1992; Wood, Stoltz, Van Ness, \& Taylor, 2018). Cultural schemas condition everything - from the most ideal things such as the concept of strategic visions (Aktaş, Çiçek, \& Kıyak, 2011; Miranda, Kim, \& Summers, 2015) to material issues such as group work (LangfieldSmith, 1992) and performance (Arditi, Nayak, \& Damci, 2017; Corritore, Goldberg, \& Srivastava, 2020; Rofcanin, Las Heras, \& Bakker, 2017). However, even when studies take into consideration individual and groups and levels within organizations (Harris, 1994), most of them aim at understanding cultural schemas based on 'consensus' degree (Basov \& Brennecke, 2017; Garro, 2000; Hofstede, Neuijen, Ohayv, \& Sanders, 1990; Oberg et al., 2017).

The fundamental matter about such consensual approaches to organizational culture lies in the fact that they suffer from conceptual and methodological issues. In conceptual terms, it is necessary emphasizing that organizational actors who share the same meaning schema do not necessarily have the same opinion about something (Goldberg, 2011; Hunzaker \& Valentino, 2019). Sharing cultural schemas means that individuals agree with judgment criteria, even if their opinions are different from each other (Rawlings \& Childress, 2019). These judgments are not based on isolated assessments, but on assessments and judgments that, in their turn, form complex meaning networks (Emirbayer, 1997; Mohr \& White, 2008).

In methodological terms, conventional statistical and analytical methods were not capable of capturing cultural schemas fully, since they did not take into account two principles, namely: relationality, whose meanings and attitudes do not emerge from entities in isolation, but from relationships between them; and multiplicity, according to which respondents organize themselves into groups based on simultaneous patterns of similarity and divergence between opinions (DiMaggio, Sotoudeh, Goldberg, \& Shepherd, 2018). Directly speaking, there was no formal method that captured the tightness of belief systems in isolation (Martin, 2002), that is, patterns of respondent's interpretation in the absence of consensus.

In light of these conceptual and methodological challenges, Goldberg (2011) has developed a technique called relational class analysis (RCA) to capture shared meanings through relationships between answers given to a particular questionnaire. This technique uses a measure of schematic similarity called relationality to compare respondents based on patterns of association among all answers, rather than on individual answers. It has been recurrently used in studies about cultural taste (Goldberg, 2011; Daenekindt, 2017), public opinion (Baldassarri \& Goldberg, 2014; Wu, 2014), and organizational innovation (Miranda et al., 2015).

Boutyline and Vaisey (2017) have pointed out a series of formalization and accuracy issues in RCA, which led Boutyline (2017) to develop an improved method capable of capturing meaning schemas based on the correlation between respondents' choices. This method, which is called correlational class analysis (CCA), has already been used in different fields such as public opinion (Barbet, 2020; Daenekindt, Koster, \& Van der Waal, 2017; Hunzaker \& Valentino, 2019) and consumption of cultural products (Daenekindt, 2019; Rawlings \& Childress, 2019). Although RCA and CCA were developed to capture cultural schemas, the management literature in the field lacks empirical studies focused on using these methods to map organizational culture schemas.

In order to fill this gap, the current tutorial article used correlational class analysis (CCA) to map organizational cultural schemas. CCA was operationalized through the 'corclass' package in the $\mathrm{R}$ software, whose application is detailed in the readme.pdffile. It was applied to a survey conducted with 207 workers from different companies, based on a scale of organizational values adapted to the Brazilian context, which was developed by Ferreira, Assmar, Estol, Helena, and Cisne (2002). First, analyses conducted in the current study have pointed toward two different classes, which were called reactive and resilient schemas. These classes did not operate as predictor variables; however, since they showed different covariance structures between respondents' attitudes, they revealed effects that would have been ignored in the full sample and that would not have been captured through any other grouping method. It is worth emphasizing the importance of identifying correlational classes by showing that each class has its equifinality, i.e., the effect of organizational variables and attitudes toward organizational values affect employees' appreciation and satisfaction differently.

Assumingly, the CCA application can be useful for three reasons. First, although research about shared meaning schemas has gained prominence in cultural studies (Hunzaker \& Valentino, 2019; Rawlings \& Childress, 2019), it has been ignored in organizational studies, despite the acknowledgment that organizational culture manifests itself through shared schemas (Harris, 1994; Miranda et al., 2015). Second, the method introduced in the current study 
enables a quantitative way of capturing shared meanings considering the 'tightness' between beliefs (Martin, 2002; Rawlings \& Childress, 2019), not just the consensus or dissension among respondents. CCA goes beyond the mere agreement between respondents - something that has been already captured by cluster analysis (Boutyline, 2017; DiMaggio et al., 2018). Indeed, new hypotheses can be outlined in the management field to open ways to investigations that go beyond the study of cultural schemas. Third, as the CCA application was already detailed in a tutorial, the learning curve can be significantly shortened, thus increasing its potential usage.

The current tutorial article was structured in four different sections. The first section presents the fundamentals of correlational class analysis (CCA), whose basis lies in the concept of shared meaning schemas. In order to do so, its original method, relational class analysis (RCA), as well as corrections and formalizations promoted by Boutyline (2017) in CCA development, was defined. The second section presents data collection procedures and specifies the operation of the scale applied to organizational values, which was used as an application example. The third section runs the CCA by pointing out how schematic classes are generated and how they can be defined, as well as specifies the steps to be taken to reproduce the analyses. Besides, it shows that the CCA method is different from cluster analysis. The study sample is divided based on the two identified classes - reactive and resilient —; where two regression models are used to show how each schema conditions the effect of organizational and attitudinal variables on employee appreciation and satisfaction. Finally, the fourth section discusses the results and presents the advantages and implications of using the correlational class analysis to capture organizational phenomena.

\section{Schemas as consensus and as tightness}

Schemas or shared meanings are complex structures of mental representations (Goldberg, 2011), either innate or acquired through experience and acculturation (Zerubavel, 1997), which organize knowledge about reality (Strauss \& Quinn, 1997). They play a key role in cultural analysis because individuals' world experiences are understood through them (DiMaggio, 1997; Hunzaker \& Valentino, 2019). Thinking about culture as schemas leads individuals to imagine that although culture is embodied by individual cognitive structures, it also reflects socialization and information exchange processes at the collective sphere, whose meanings tend to be shared. Hence, the usefulness of thinking about shared meaning schemas, since they simultaneously reside in individuals as a cognitive trait and the collective as reference frames (Wood et al., 2018).
Elementally, from a cultural perspective, the meaning of things - events, objects, and experiences - refers to how the subjects interpret them, attributing quality and significance to their experience. Collectively, the process of interaction between subjects inevitably leads to interpretation to be shared, fostering the creation of systems of meaning. This process is both social, because it operates in groups, and cognitive and affective, occurring reflexively from the sense-making reality. As a social process, the formation of shared meanings operates as 'consensus' (Aßfalg \& Erdfelder, 2012; Romney, Weller, \& Batchelder, 1986). However, as a cognitive process, the formation of meaning schemas operates as 'tightness' (MacQueen, 2020; Martin, 2000, 2002; Rawlings \& Childress, 2019; Wood et al., 2018).

A consensus-based cultural approach understands that there are shared meanings when there is an agreement between a group of respondents about one or more interpretations (Aßfalg \& Erdfelder, 2012; Martin, 2002). Therefore, there is some degree of consensus when there is a greater agreement between individuals and greater disagreement when they disagree with interpretations. A cultural approach based on tightness looks at respondents' patterns of interpretation in terms of how they organize their ideas and preferences, whose pattern emerges through complex meaning networks (Emirbayer, 1997; Mohr \& White, 2008). In a nutshell, there is full consensus when people interpret some fact equally, and there is full tightness when they are based on the same reasons and justifications.

Consequently, if shared meaning schemes emerge from both consensus and tightness, of course, there can be shared meaning in three conditions: (a) when there are consensus and tightness (people agree with the answers and have the same pattern of interpretation); (b) when there is only consensus (when people agree with the reasons but disagree with the rules of judgment); (c) when there is only tightness (there is disagreement, but the patterns of interpretation are the same). There are not many theoretical and empirical doubts about conditions a and $\mathrm{b}$. However, condition $\mathrm{c}$ has always been a theoretical and methodological challenge.

In condition c, saying that individuals can share meaning schemas does not mean that they agree with each other or that they have the same opinion about a given subject (Goldberg, 2011). It means that they share judgment parameters embedded in meaning networks (Emirbayer, 1997; Mohr \& White, 2008) that attribute similar relevance and significance to a given topic. Thus, the meaning given to any particular element is not based on its isolated assessment, but on its reference to other elements (DiMaggio et al., 2018) connected through a web of logical, psychological, and sociological implications (Martin, 2000). For example, individuals may disagree on the legality of abortion, but they can use the same reason to justify their opinion, namely: the religious one. In this case, they differ in 
opinion, but they converge on reasons. Therefore, their schemas tend to be similar, despite their discrepancy of opinions.

In Figure 1, we illustrate the difference between consensus and tightness using the four dimensions of the scale of organizational values (Ferreira et al., 2002). On a 5-point agreement scale (the higher the value, the greater the agreement), subject $\mathrm{A}$ interprets that there is no hierarchical rigidity, nor a meritocratic professional logic in his company, but he understands that cooperative professionalism and the employee's appreciation and satisfaction is maximum.
However, subject B has a completely opposite interpretation: no employee appreciation and satisfaction and no cooperative professionalism; total hierarchical rigidity and meritocratic professionalism. As can be seen, there is no consensus between $\mathrm{A}$ and $\mathrm{B}$, on the contrary, there is total dissent, as the responses are totally antagonistic. However, respondents A and B have a total tightness in their schemes for assessing organizational values. Although they disagree, their interpretation schemes are mirrored, as they understand the four items in the same way, but with contrary evaluations.

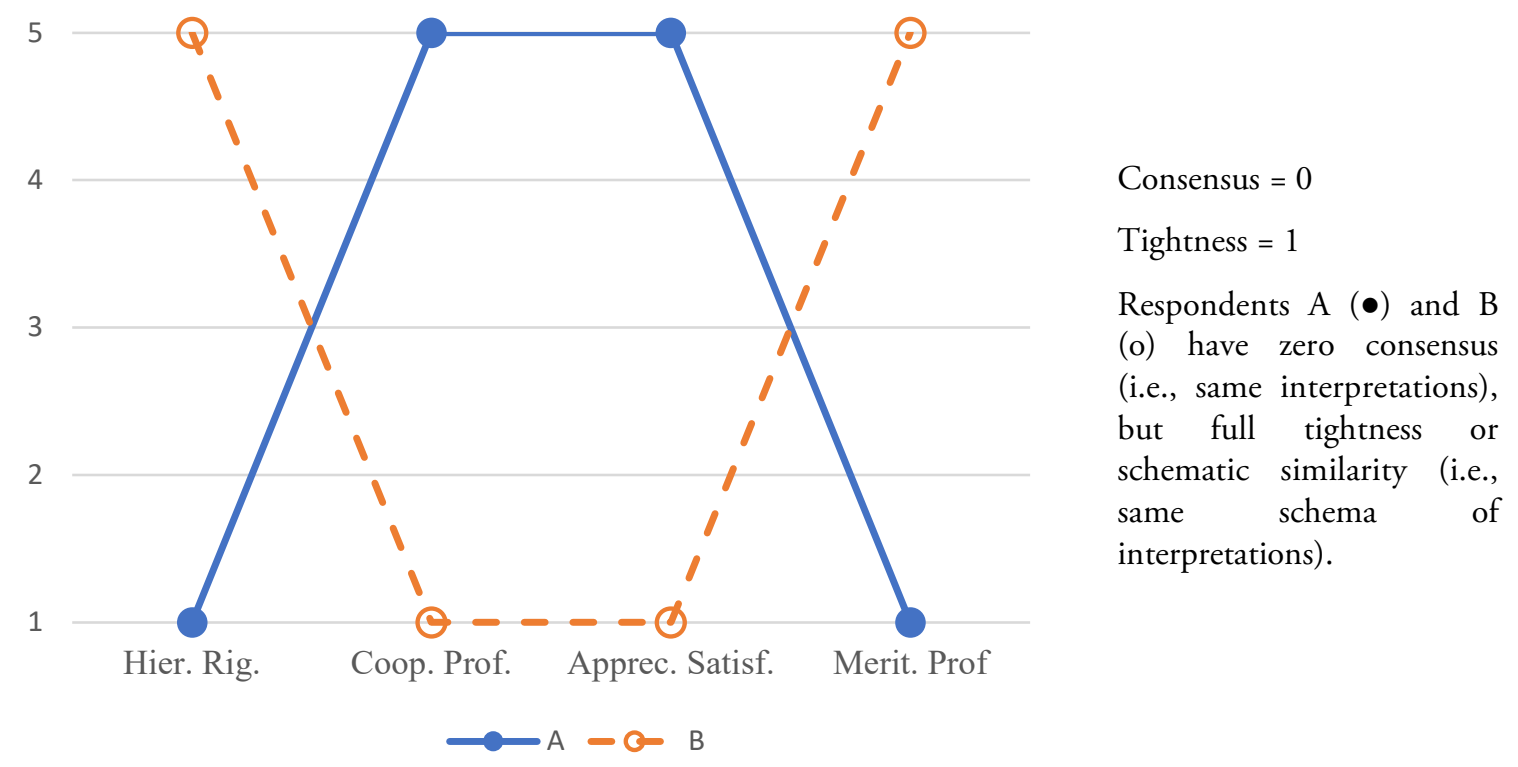

Figure 1. Dyad between two hypothetical cases with low consensus, but high tightness.

Figure 1 shows the stages of the R code, from data importation, testing for ARCH effects, estimation, and selection of models and results presentation. Legend: Hier. Rig: Hierarchical Rigidity and Competition; Coop. Prof.: Cooperative Professionalism; Apprec. Satisf.: Employee Appreciation and Satisfaction; Merit. Prof.: Meritocratic Professionalism.

This figure reproduces the content of: Rawlings, C., \& Childress, C. (2019). Emergent Meanings: Reconciling Dispositional and Situational Accounts of Meaning-Making from Cultural Objects. American Journal of Sociology, 124(6), 1763-1809. https://doi.org/10.1086/703203; but adapted to the data of this study. The intention is to demonstrate that shared schemas can be formed by consensus or tightness.

In substantive terms, we can say that there is a tension in the appreciation of the four dimensions: on the one hand, cooperative professionalism and appreciation and satisfaction are intrinsically related; on the other hand, hierarchical rigidity and meritocratic professionalism are also intrinsically related to each other, but in an antagonistic way with the first two dimensions. This pattern suggests that a decrease in the sense of cooperation and appreciation would increase, in the same proportions, the sense of rigidity and meritocratic assessment. In theoretical terms, cultural schemes are belief systems that incorporate elements that, even though they appear to be antagonistic, are intrinsically distributed (Martin, 2000), whose degree of organization is attributed to the connection between these elements (Boutyline \& Vaisey, 2017; DiMaggio et al., 2018; Martin, 2002).

\section{Measuring schemes as tightness: the relational (RCA) and correlational (CCA) classes}

Measuring consensus among respondents, through clusters analysis, consensual analysis, or analysis between groups and levels, or even measuring the similarity between beliefs, through factor analysis, has never been a major 
challenge. However, capturing shared meaning schemas as tightness has always been a methodological challenge (Boutyline, 2017; Goldberg, 2011; Martin, 2000), mainly when one aims at making their structures intelligible while preserving the heterogeneity inherent to such schemas (Boutyline \& Vaisey, 2017; DiMaggio et al., 2018). Thus, it was necessary developing a methodological approach capable of capturing schemas based on relationships between answers given to a questionnaire, since the same answer can have different meanings (DiMaggio et al., 2018). Relational methods, such as social network analysis, are a viable analytical alternative to capture the structure of relationships between beliefs.

Although there were studies that analyzed cultural schemes such as tightness, most were qualitative (e.g., Garro, 2000; Langfield-Smith, 1992), or at most, a combination of different quantitative strategies (e.g., Basov \& Brennecke, 2017; Martin, 2002). The relational class analysis (CCA) developed by Goldberg (2011) was the seminal work that formally instituted a method that captures the tightness of belief systems. Additionally, as cultural schemes are collective, Goldberg's method has also defined ways of creating classes of respondents who share the same belief systems.

RCA uses relationality as a schematic similarity measure, which compares the individuals based on patterns of relationships between their attitudes, rather than on their attitudes themselves. Inspired by a structuralist and relational logic, Goldberg (2011, p. 1399) conceptualizes relationality as "the extent to which two individuals show a similar pattern of association between measures of opinion about issues associated with a specific social domain." Operationally, the relationality measure is used to create a schematic similarity matrix between respondents. Then, in a second stage, RCA uses an algorithm to maximize modularity in the schematic similarity matrix (Newman, 2006), identifying an optimal number of classes, whose respondents share the same meaning schemas (Baldassarri \& Goldberg, 2014; Goldberg, 2011). However, despite the great advancement provided by the method developed by Goldberg (2011), Boutyline (2017) has questioned RCA accuracy in mapping cultural schemas.

Boutyline (2017) has highlighted some inconsistencies in the RCA method. The first one refers to the lack of a formal definition to indicate how a group of respondents shares a cultural schema. On the other hand, Goldberg (2011) has illustrated RCA's intuition in a graph (Figure 2 ), which represented the musical taste of four respondents: A, B, C, and D. Each respondent pointed out how much he likes a given music style; their choices ranged from 1 (strongly dislike) to 5 (strongly like).

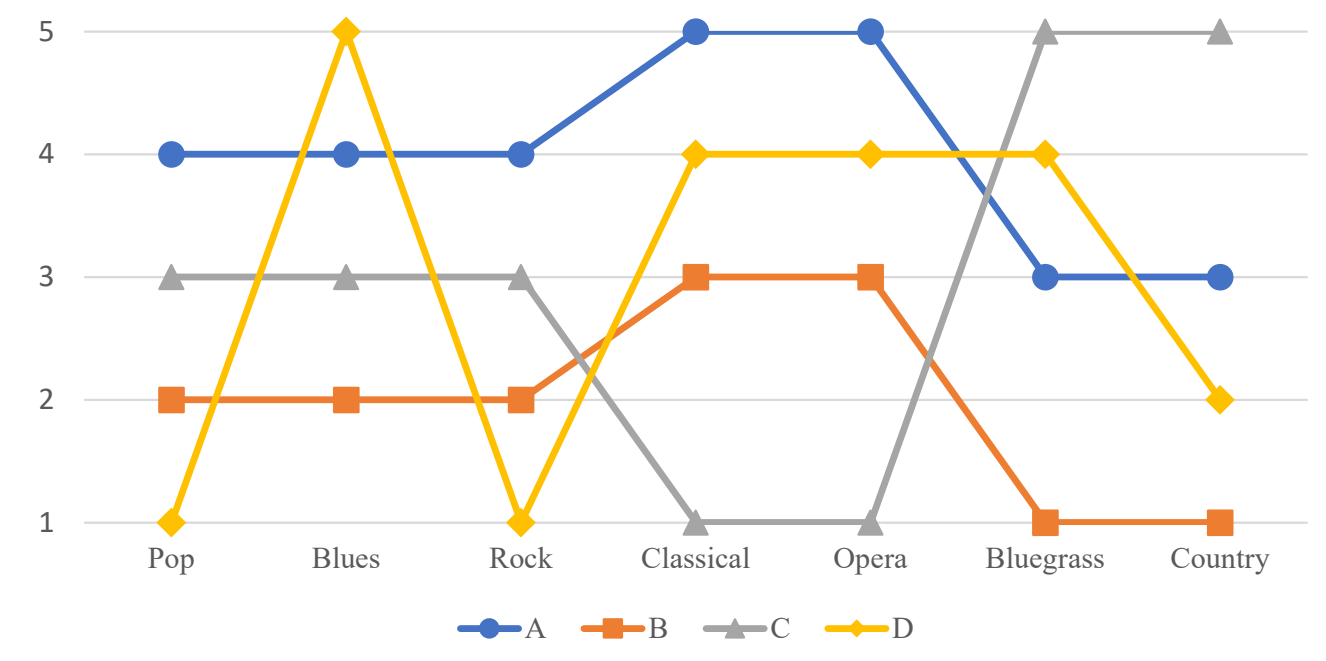

Figure 2. Musical taste of four respondents.

Each line represents the choices made by each respondent, which ranged from 1 (strongly dislike) to 5 (strongly like). The figure points out that even if there is no agreement in terms of musical taste, respondents may have similar choice patterns. Source: reproduced from Goldberg, A. (2011). Mapping shared understandings using relational class analysis: The case of the cultural omnivore reexamined. American Journal of Sociology, 116(5), 1397-1436. https://doi.org/10.1086/657976; and Boutyline, A. (2017). Improving the measurement of shared cultural schemas with correlational class analysis: Theory and method. Sociological Science, 4(15), 353-393. https://doi.org/10.15195/v4.a15 
Based on the answers, one can infer the 'schematic similarity' between each respondent. Boutyline (2017) presents the algebraic operations that represent them. While respondent $A$ likes pop music, blues, and rock and roll, he strongly likes classical music and opera and is indifferent to bluegrass and country music: $A=[4,4,4,5,5,3,3]$. On the other hand, $B$ dislikes pop music, blues, and rock, he is indifferent to classical music and opera and he strongly dislikes bluegrass and country music: $B=[2,2,2,3,3,1,1]$. Despite their different choices, $A$ and $B$ have the same pattern, according to which $B=A-2$, since $B$ assessed all musical genres in the same descending degree $(-2)$ as $A$. Therefore, $A$ and $B$ are schematically identical. Respondent $C$, in his turn, is indifferent to pop music, blues, and rock and roll, he strongly dislikes classical music and opera and he strongly likes bluegrass and country music: $C=[3,3,3,1,1,5,5]$. According to Boutyline (2017), $C$ presents the same relative pattern as $A$ and $B$; however, all choices are vertically $[C=2(-1) A+11)]$ or equivalently shifted, inverted and amplified $[C=2(-1) B+7]$. Finally, respondent $D$ strongly likes pop music and rock and roll, he strongly likes blues, likes classical music, opera, and bluegrass, and dislikes country music: $D=[1,5,1,4,4,4,2]$. Unlike the other respondents, $D$ opposes bluegrass and country, but he does not oppose bluegrass and opera. Thus, as Boutyline (2017) points out, no inversion, multiplication, or change of pattern can bring him closer to $A, B$, and $C$. Therefore, it is possible saying that $D$ follows a schema different from the others.

Based on this example, Boutyline (2017) proposed that two respondents have exactly the same schema if: (a) their answers are identical $(Y=X)$; (b) their answers are exactly inverse $(Y=-X)$; (c) their answers are uniformly more extreme $(Y=k X)$; (d) the answers given by one are uniformly more positive than those given by the other $(Y=X+b)$; and (e) any combination of conditions b, c, and $\mathrm{d}$. Based on these conditions, it is possible inferring that "two respondents $(X$ and $Y$ ) follow exactly the same schema if, and only if, there is a linear transformation capable of producing a vector of responses from the other or, more formally, if there are constants $b$ and $k \neq 0$, wherein $Y=k X+b "$ (Boutyline, 2017, p. 357). Thus, based on Boutyline (2017), it is possible inferring that two actors present greater 'schematic similarity' when the existence of both $k$ and $b$ is maximized, either in the functional form or through approximations.

As previously mentioned, Goldberg (2011) has proposed a schematic similarity measure called relationality $\mathrm{R} i j$, wherein $R$ is the measure of similarity between $i$ and $j$, which ranges from -1 to 1 . Since extreme values indicate the same schema, relationality operates with absolute values $|\mathrm{Rij}|$. However, according to Boutyline (2017), Goldberg (2011) has developed a measure inadequate and poorly accurate to capturing shared schemas.
Given this limitation, Boutyline (2017) has advocated that it is necessary finding another measure of schematic similarity capable of preserving the same conditions, i.e., $X$ and $Y$ follow the same schema if there are constants $b$ and $k \neq 0$, wherein $Y=k X+b$. If one takes into consideration that $X$ and $Y$ have finite variation other than zero, as well as conditions according to which $X$ and $Y$ do not show variance in the answers, then $k \neq 0$. Thus, a measure appears to be appropriate when it takes into consideration that two respondents are schematically closer to each other when they are linearly more dependent on one another, as in the case of Pearson's correlation (Boutyline, 2017).

Quite simply, Boutyline (2017) demonstrated that using Pearson's correlation to verify the schematic similarity of the cases (not between variables, as is currently done) meets all the logical properties exemplified in Figure 2, in addition to being easily computed. Then he replaces $|\mathrm{R} i j|$, Goldberg's relationality measure, for the level of correlation between cases $|S i j|$, calling this measure correlational class analysis (CCA). Therefore, the stronger the correlation between $i$ and $j$, the greater the schematic similarity $S$. After identifying the schematic similarity between each case, the CCA uses the same modularity maximization algorithm (Newman, 2006) to identify the optimal number of partitioning, dividing the sample into groups of schematic classes.

Boutyline (2017) has compared the results of his newly created measure (CCA) to RCA based on Pearson's correlation between respondents. CCA produced a much better result than RCA in a sample comprising 800 respondents, who have been originally investigated by Goldberg (2011). CCA superiority over RCA was also proven through the simulation of 5,000 samples from the same data bank. Boutyline (2017) used the normalized mutual information (NMI) test, which measures the accuracy of network partition algorithms, and found CCA adjustment equal to 0.97 (the maximum value is 1 ), whereas RCA adjustment was 0.74 . CCA was the most accurate in all conditions in simulations of schematic relationships other than the linear ones. Finally, the author has analyzed whether sample partition into groups was more informative than the full sample - he used structural equation modeling (SEM) to analyze multiple groups. Results of the Akaike and Schwarz tests have indicated that both RCA and CCA were more accurate than the full sample; however, CCA was more accurate than the RCA.

Thus, given the analytical superiority of CCA over RCA, as well as its greater coherence with the formalization of shared cultural schemas, the current study used correlational class analysis to capture organizational culture schemas. 


\section{Data and measurements}

Data were collected in a sample of workers from different companies in the metropolitan region of Curitiba (PR) to enable analyzing their organizational culture schemas - these workers were the observation unit. The sample was selected by convenience; data were collected through the application of a closed questionnaire, whose questions investigated employees' attitudes toward the organizational values they work in, as well as a series of information about organizations and individuals. Thirty-seven (37) collaborators were properly trained to apply five to ten questionnaires in different organizations. Thus, the data collection process resulted in 246 answered questionnaires (6.6 questionnaires per collection agent, on average). However, some of these questionnaires presented biased answers, as well as a large number of unanswered questions, which resulted in the exclusion of 11 of them. Besides, 28 cases were excluded because the correlational class analysis technique does not allow treating missing values (Boutyline, 2017). Thus, the final sample was composed of 207 cases. The responses to the questionnaire were organized in a cross-sectional data matrix, with cases in the rows and variables in the columns. There is no additional special treatment for running CCA, which allows the technique to be used in other data structures, such as panel data.

\section{Capturing organizational culture}

Contemporary theories about culture assume that it is formed based on shared meanings (Goldberg, 2011; Mohr \& White, 2008), whose cultural schemas emerge from individuals' cognitive appreciation of social reality (DiMaggio, 1997; Strauss \& Quinn, 1997; Wood et al., 2018; Zerubavel, 1997). It would not be different for organizational culture, whose cultural schemas emerge from workers' appreciation about the organization (LangfieldSmith, 1992). Thus, it is necessary to capture organizational culture based on attitudinal scales (DiMaggio et al., 2018).

The choice was made to evaluate organizational culture based on values, although acknowledging the existence of other elements such as beliefs, myths, and artifacts (Schein, 1992), which are the ones most directly representing cultural schemas. Among different alternatives for the operation of organizational values, the current study has adopted scales already validated and used in Brazil - which is the current research context - , based on the premise that they would enable greater face validity (Netemeyer, Bearden, \& Sharma, 2003).

Considering these elements, we choose the scale of organizational values of Ferreira et al. (2002), who measured a total of 55 items using a 5-point Likert scale, whose measurement ranged from 'it does not apply to my company in any way' to 'it totally applies to my company.'
The aforementioned authors used studies conducted by Calori and Sarnin (1991) and Hofstede, Neuijen, Ohayv and Sanders (1990) to substantiate the questions of a semistructured questionnaire, whose goal was to identify values and organizational practices among business executives.

Ferreira et al. (2002) have identified four dimensions corresponding to the values: cooperative professionalism (23 items); hierarchical structure rigidity (13 items); competitive and individualistic professionalism (8 items); employee satisfaction and well-being (11 items). Although having these four previously defined dimensions at hand, we made another attempt to identify dimensionality based on principal component analysis due to several indications of divergence between factors deriving from empirical evaluations conducted in different cultural contexts (Calori \& Sarnin, 1991; Hofstede et al. 1990).

Similar to Ferreira et al. (2002), factors were herein extracted based on the principal component analysis. First, their adequacy was evaluated through Kaiser-Meyer-Olkin $(\mathrm{KMO}=0.886)$ and Bartlett's sphericity tests $(\mathrm{p}<0.001)$, which presented satisfactory results. Next, the number of factors was evaluated based on the scree plot method, which pointed toward four dimensions that met the number identified by Ferreira et al. (2002); however, there was $47.5 \%$ total variance explained - this value was higher than the 34\% found by Ferreira et al. (2002). Still, based on Ferreira et al. (2002), the four factors were subjected to Varimax orthogonal rotation, as well as to oblique (Oblimin) rotation, to improve factor-loading interpretation. The items identically fit each of the factors, in both rotation methods. Thus, the Varimax rotation output, which is easier to be interpreted, was used in the current study. Items presenting factor loading lower than 0.4 were excluded from the study, as suggested by Hair, Black, Babin, and Anderson (2018). Finally, the reliability of the analyzed dimensions was analyzed through Cronbach's alpha test; items reducing such reliability were discarded, whereas alpha values greater than 0.7 were considered reliable (see Nunnaly's criterion, 1978). The scale was reduced to 47 items, which were grouped into four factors (one for each dimension of the organizational values) using the arithmetic mean (see items, codes, and factor loading in Appendix A of the readme.pdffile).

Table 1 presents the four herein identified factors. Two factors could be interpreted in the same way as Ferreira et al. (2002), namely: cooperative professionalism and employee satisfaction and appreciation. However, competition and hierarchical rigidity formed a single factor in the current study. Meritocratic professionalism was not assessed in the study by Ferreira et al. (2002), but it stood out as a factor in the present analysis. 
Table 1. Descriptive statistics and correlations among organizational values dimensions.

\begin{tabular}{lcccccc}
\hline & Items & Mean & $\begin{array}{c}\text { Variance } \\
\%\end{array}$ & $\begin{array}{c}\text { Cronbach } \\
\text { alpha }\end{array}$ & (2) & (3) \\
\hline 1. Cooperative Professionalism & 17 & 3.7 & 15.9 & 0.93 & -.393 & .647 \\
2. Hierarchical Rigidity and Competition & 13 & 3.0 & 12.8 & 0.90 & .609 & -.376 \\
3. Employee Appreciation and Satisfaction & 10 & 3.2 & 11.8 & 0.92 & -.202 \\
4. Meritocratic Professionalism & 7 & 3.3 & 7.0 & 0.77 & .597 \\
\hline
\end{tabular}

Note. All correlations are significant at the level of $0.01, \mathrm{n}=207$. In addition to pointing out the number of items, the mean, variance explained in the exploratory factor analysis and reliability (Cronbach alpha), the table shows the correlation between the dimensions.

The first factor covered elements associated with the appreciation of aspects such as collaboration, creativity, initiative, acceptance of the organization's ideals, professionalism as a virtue, among others. Together, these aspects suggested the designation of cooperative professionalism to this factor, which comprised 17 items, whose variance explained was $15.9 \%$ and Cronbach's alpha was 0.93 . The second factor comprised 13 items whose expressed values were almost opposite to the first factor: no stimulus or reward to creativity and initiative, promotion limited to the formal structure, and, mainly, the incentive to the competition. These aspects were used to name the factor as 'hierarchical rigidity and competition', whose variance explained was $12.8 \%$ and whose alpha was 0.90 . The third factor comprised 10 items, which were mainly associated with concern with employees' well-being and satisfaction, and the association between such satisfaction and productivity. This factor was called 'employee appreciation and satisfaction', whose variance explained was $11.8 \%$ and whose alpha was 0.92 . Finally, the last factor refers to values close to the first one; however, they emphasize aspects such as commitment to the company and competence as a promotion means in the organization - this factor was called 'meritocratic professionalism' and encompassed seven items whose variance explained was $7 \%$ and whose alpha was 0.77 .

\section{Correlational class analysis application}

To illustrate the utility of correlational class analysis, organizational culture schemas were mapped based on the 47 items comprising the organizational values scale by Ferreira et al. (2002). The items are available in the Organizational_Culture_CCA.sav database, which, in its turn, is available in the supplementary material of the current tutorial article. Concerning data structure, both Goldberg (2011) and Boutyline and Vaisey (2017) assume that variables used in relational and correlational classes: (a) must be a ratio or interval variables; (b) preferably show the same measurement level; (c) present linear association with each other; and (d) have reliable dimensions. However, both Boutyline (2017) and DiMaggio et al. (2018) used low internal consistency scales, which had different measurement levels and were based on binary variables. The most important is that the chosen variables have some logical connection between them, whose 'tightness' between variables refers to interconnectivity among beliefs, values, or attitudes (Miranda et al., 2015; Rawlings \& Childress, 2019). Boutyline (2017) has demonstrated that RCA and CCA were robust methods when such assumptions were not met, as well as when associations between variables were not linear. In most cases, CCA performance in creating classes was better than that of RCA, mainly when the assumptions were met - which was the case of current data.

Correlational class analysis (CCA) becomes operational through the 'corclass' package (Boutyline, 2017) in the R software, whose installation instructions, as well as the definition of additional packages necessary to follow this tutorial, are available at the readme.pdf file, which, in its turn, is available in the supplementary material section of this tutorial paper. Codes, functions, and parameters necessary to run this tutorial are also described there; they were herein omitted to make result explanation easier. Thus, it is strongly recommended to read the readme.pdffile, whose steps must be followed to enable effective CCA application. Anyway, the current tutorial indicates the part of the readme.pdffile where each analysis presented in the text was generated.

The results were divided into four different stages. First, correlational classes were generated to identify the schematic similarity between the cases and divide the sample into classes, in which two partitions were identified by the modularity maximization algorithm (Newman, 2006). Second, these classes were defined based on visual techniques of social network analysis and heat maps generated in the previous stage. Third, it was demonstrated that classes empirically differ from clusters to avoid confusion with other database partitioning techniques. Fourth, it was shown how correlational classes can operate as distinction schemas; two regression models, one for each class, were run to enable seeing how effects between them can be different.

\section{Generating relational classes}

To generate the correlational classes, four arguments must be specified (see step 5 in the readme.pdffile): (1) define the database; (2) specify whether correlation matrices should 
be filtered by significance (TRUE increases the accuracy of CCA); (3) point out the significance cutoff adopted (0.05 in this article); (4) print the details on the screen (TRUE was the choice). So, after calculating the schematic similarity of each of the cases, the CCA's modularity maximization algorithm divided the sample of 207 cases into two correlational classes: one comprising 105 cases (50.7\%); the other one, 102 (49.3\%).

As previously stated, correlational classes are not clusters, although they classify individuals. Thus, there is no judgment homogeneity on organizational values. Therefore, describing the mean of each class for each item would be poorly informed. CCA aims at aggregating individuals who agree about the relevant arguments or items, although they do not agree with each other. Consequently, classes aggregate members who present similar choice patterns between each pair of variables, which, in the present case, refer to the 47 items in the scale. This procedure leads to increased covariance within each class; thus, analyzing the correlation matrices of each relational class can be more productive (Goldberg, 2011).
However, large matrices are not very intuitive when it comes to interpreting systems of variables because they require powerful graphic resources. Since the network metaphor fits very well with the assumptions and intuitions of belief and value systems, these classes are often represented through social network analysis graphs (Boutyline \& Vaisey, 2017; DiMaggio et al., 2018; Goldberg, 2011). Figure 3 depicts the correlation matrix generated for each class based on a network graph (step 5.1 of the readme.pdf file). Each node in the network refers to an item in the scale; the edges point toward a significant correlation between each item and edge thickness represents the correlation degree. Besides, the heat map for each correlation matrix was plotted (step 5.2 of the readme.pdf file). Each heatmap box represents a cell in the correlation matrix. As there are 47 items on the scale of organizational values, the heatmap boxes represent the correlation between all items. Intense blue frames indicate strongly positive correlations, whereas intense red frames indicate negative correlations. Low and moderate correlations are represented in lighter shades. Together, graph and heatmap help define schematic classes.
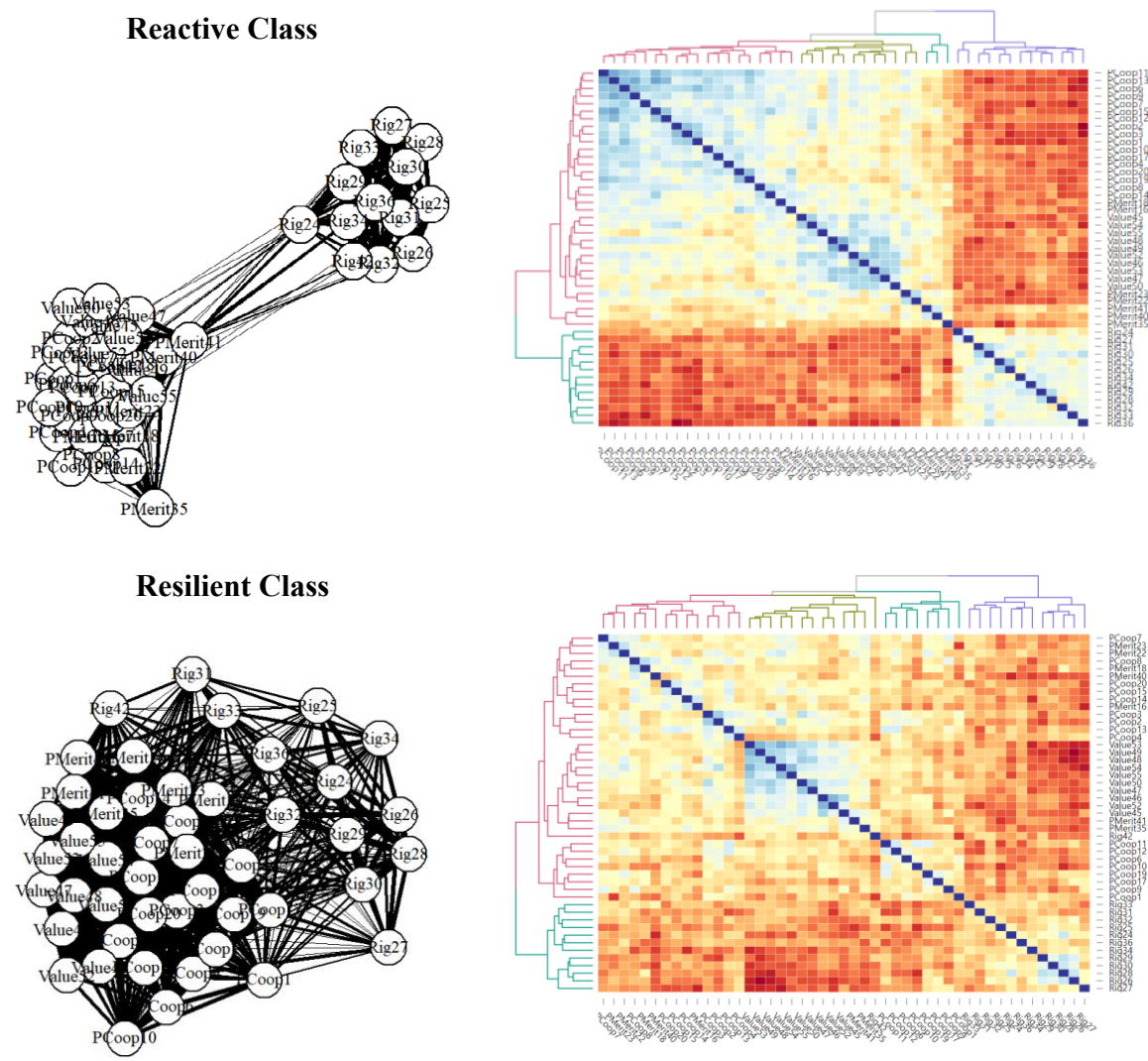

Figure 3. Relational class network diagrams and heatmaps.

Graphs and heatmaps are useful to illustrate relationships between variables. Nodes in the graphs represent each item in the scale. Loops represent a significant correlation between variables $(\mathrm{p}<0.05)$; the thicker the loop, the stronger the correlation. Negative relations were omitted to improve visualization, although they were used to define classes (step 5.1 in the readme.pdf file). Significant negative correlations are highlighted in red on the heatmaps, significant positive correlations are highlighted in blue, whereas low and moderate correlations are highlighted in different shades of yellow (step 5.2 in the readme.pdffile). Supplementary material (Organizational_Culture_Classes.html) presents an interactive heatmap. 
CCA is a method for partitioning the sample into two or more classes to capture an unobserved heterogeneity. Thus, each class would represent different schemes if the correlation matrices were significantly different. Boutyline and Vaisey (2017) suggested that checking the accuracy of class partitioning should be done through multiplegroups testing techniques of correlation matrices. Then Jennrich's (1970) correlation matrix equality test was used, which pointed out that the class correlation structures are significantly different $\left(\mathrm{Chi}^{2}=2847 ; \mathrm{p}<0.001\right)$. This is consistent with the idea that each schematic class organizes its attitudes about organizational values differently.

Within each of the two correlational classes, some respondents show schematic similarity, regardless of whether there is consensus between them. Thus, in each schema, there is a part of respondents who agree with the answers, whose response values for each item are the same or close. However, there is also another portion of individuals who disagree with the answers, but have a correlation - negative in this case - between which variables are relevant. Thus, in the group of individuals who share the same schema, there will be respondents both with the highest mean value in the answers and with the lowest mean value (see Figure A1 in Appendix A). In practical terms, each class aggregates cases whose responses have a greater correlation with each other, regardless of whether the correlation is negative or not. Analyzing these correlation patterns, it is possible to identify how respondents organize their preferences, allowing them to define the schemes of each correlational class.

\section{Defining correlational classes}

In order to give sense to correlational classes, each of them was defined based on the analysis of correlation patterns between items by taking the four organizationalvalue dimensions as reference (Figure 3). The first relational class was called Reactive Schemas. Far from creating any taxonomy of cultural schemas, the goal is to illustrate how these classes can be represented. Thus, class schema 1 was called reactive because the items of cooperative professionalism, meritocratic professionalism, and appreciation dimensions antagonize (negative correlations) hierarchical rigidity and competition. Hence, the idea of reactivity: individuals in this organizational culture appreciation schema understand that different professionalism types, as well as employee appreciation and satisfaction, get compromised in situations of greater rigidity and competition, and they react to such conditions. The opposite also happens when individuals understand that there are less rigidity and competition; they show a positive attitude toward the two professionalism types and values. Based on the network graph of the reactive schema class, this outcome is represented by the distance between hierarchical rigidity and competition nodes (Rig code) and the other dimensions. The heatmap corroborates this result since its quadrants mostly showed a positive correlation between dimensions such as cooperative and meritocratic professionalism and employee appreciation and satisfaction (bluer shades). On the other hand, hierarchical rigidity and competition presented a negative correlation to other dimensions (reddish shades).

The second class was called Resilient Schemas because both cooperative and meritocratic professionalism dimensions tend to have a relatively independent relationship with hierarchical rigidity and competition dimensions; some items are even positively correlated to each other. It is possible interpreting that the two professionalism types continue to operate in the same way, regardless of whether the structures of this class are more rigid or the environment is more competitive. Cases where employees are appreciated negatively have little to do with hierarchical rigidity and competition. Based on the graph representing the network of resilient schemas, it is possible seeing that this network is more cohesive than that of the previous schema, whose nodes of the hierarchical rigidity and competition dimension (Rig code) are close to the others, mainly to the nodes of the cooperative (PCoop code) and meritocratic professionalism (PMerit) dimensions. The nodes of the employee appreciation and satisfaction dimension (Value code) are a little farther from the rigidity nodes since the correlation between these dimensions is negative. The heatmap of resilient schemas points toward the same interpretation: correlations between items in professionalism, hierarchical rigidity, and competition dimensions tend to be slightly positive (yellow shades) or slightly negative (light red shades). Based on the comparison of correlations between items in the professionalism dimensions and items in the employee appreciation and satisfaction dimension, it is possible seeing that they are less intense (yellower shades) in the class of resilient schemas than in classes of reactive schemas (bluer shades). The difference between classes reinforces the names attributed to each of them: individuals in the class of reactive schemas presented moderately proportional association between professionalism and satisfaction, whereas individuals in the class of resilient schemas presented weak or nonexistent association between these dimensions.

\section{Correlational classes versus clusters}

The task of creating correlational classes generates a new nominal variable, in which each observation unit is classified into two, or more, categories. As previously mentioned, correlational classes are not clusters. Cluster analysis methods aim at maximizing homogeneity among respondents within each group based on similar answers (consensus), whereas correlational classes aim at identifying 
cases with the same pattern of responses (schematic similarity), whose pattern may be antagonistic.

In practical terms, unlike other partitioning techniques, such as cluster analysis, which group cases by proximity invariable responses (columns), correlational classes are created by case interdependence (rows). Consequently, while within clusters there is greater homogeneity between cases, which in cultural terms refers to consensus, in classes there are cases with a greater correlation between responses, negative and positive, which refers to tightness or schematic similarity. Thus, the CCA, as well as the RCA, allowed a new way to operationalize the unobserved heterogeneity within groups of respondents that have something in common, but imperceptible in the aggregated data or other techniques. If that something in common called schemas matters, probably the causal relationships and interdependencies between variables within each class will operate differently. This allows the use of causal models and dependency techniques within schematic classes, which is mathematically unfeasible within homogeneous subgroups.

However, before using classes to compare dependency models like linear regression, it is necessary to demonstrate that correlational classes and clusters are different. To prove it, we used all 47 items in the scale of organizational values to identify homogeneous groups through the hierarchical combination of cases, based on the Euclidean distance, by using the Ward method (see step 6 in the readme.pdf file). Based on the dendrogram analysis (Figure 4), it was possible identifying two different groups, which were corroborated by the scree plot analysis. Next, two groups were generated based on the K-means method to maximize homogeneity.

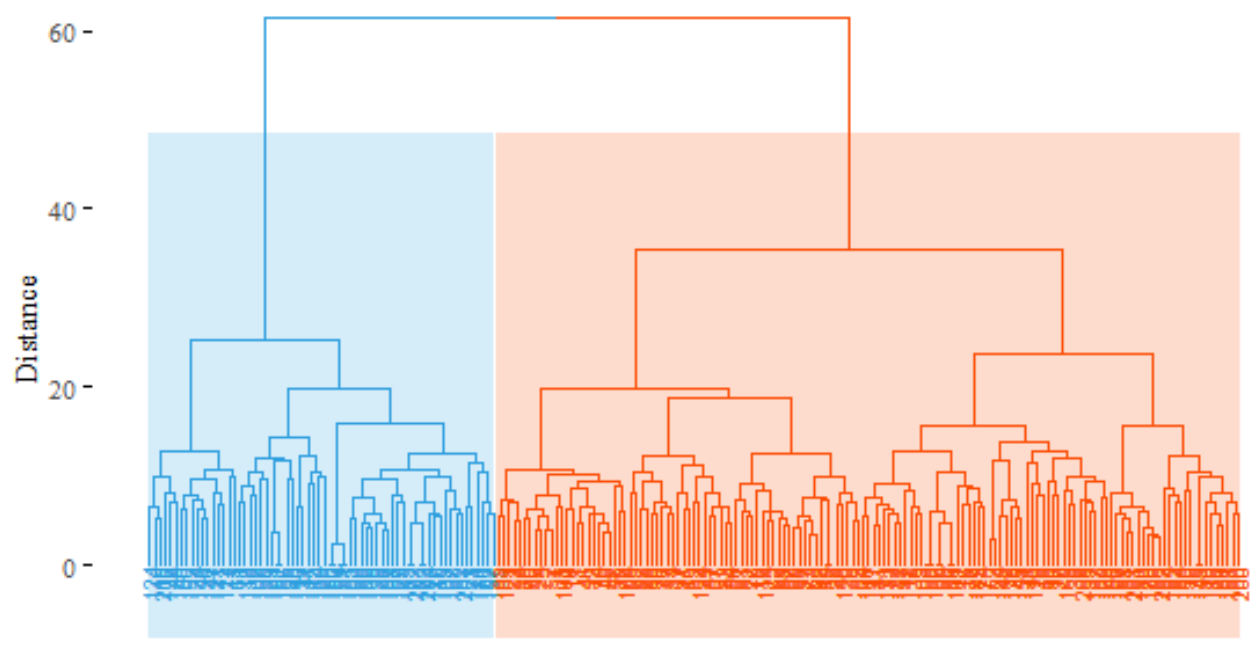

Objects

Figure 4. Identifying groups based on the organizational values scale.

The dendrogram color differences illustrate the formation of two distinct groups, internally homogeneous.

Nominal variables representing the two classes were crossed in a crosstab to check whether these classes were different from the two homogeneous clusters. It was done by testing differences between categories based on the chisquare and Cohen's Kappa association tests (see step 7 in the readme.pdffile). Both tests have shown that classes and clusters were significantly different from each other $(\mathrm{p}<0.05)$ - Kappa association coefficient was $58.3 \%$, i.e., there was an overlap in $58.3 \%$ of cases and disagreement in $41.7 \%$ of them.

Intending to assure that differences did not result from the clustering method, the association between correlational classes and clusters generated by another association method — the two-steps, Schwarz's Bayesian criterion was tested. Results have indicated that they were significantly different from each other and presented a lower association with one another $(\mathrm{Kappa}=52.1 \%)$. Classes and clusters formed from all four scale factors were also compared to each other. Results have also indicated differences: the Kappa between correlational classes and the cluster generated based on the K-means method was $54.5 \%$, whereas the group generated based on the two-steps method recorded Kappa equal to $44.2 \%$. These additional analyses were omitted in the readme.pdffile to simplify the script in the R software. In short, they pointed out that correlational classes and clusters used empirically different classification criteria. 


\section{Using correlational classes as differentiation schemas}

After all, what are correlational classes used for? Correlational classes allow differentiating individuals in different cultural schemas with different logics of appreciation by preserving cultural multivocality (Goldberg, 2011). Since these classes identify members who share the same meaning structures without necessarily having the same normative position (DiMaggio et al., 2018), the effect of variables affecting attitudes toward organizational culture can change within each class. Thus, correlational classes go beyond cultural differences in terms of positions and capital distribution (Bourdieu, 1984). They also go beyond the difference resulting from the organizational structure (see Hofstede et al., 1990), which treats such aspects as independent variables. Classes and their underlying meaning structures (construals) can also operate as differentiation mechanisms (Goldberg, 2011; DiMaggio \& Goldberg, 2018).
How then do you evaluate the effect of these mechanisms underlying the schematic classes? The answer is simple: running dependency models in parallel between classes. Thus, to exemplify such use of correlational classes, two regression models (see step 8 of the readme.pdffile) were run by assuming the employee appreciation and satisfaction dimension as a dependent variable. This variable is often used as a partially endogenous element in studies about culture and organizational climate (Geisen et al., 2019), which explains its selection. The other three dimensions of organizational value escalation - cooperative professionalism, meritocratic professionalism, hierarchical rigidity, and competition - were incorporated as predictors to demonstrate how the effect of each dimension can change in each class. Two recurring structural variables investigated in studies on organizational culture (Hofstede et al., 1990; Knoll, Neves, Schyns, \& Meyer, 2020) - i.e., the number of employees and company age - , as well as a variable often associated with the best management practices (Bansal \& Clelland, 2004; Raines, 2003) - i.e., the ISO 14000 certification - , were also adopted in the current study.

Table 2. OLS coefficients between relational classes.

\begin{tabular}{|c|c|c|}
\hline & \multicolumn{2}{|c|}{ Dependent variable: Employee Satisfaction and Appreciation } \\
\hline & Model (1): Reactive Class & Model (2): Resilient Class \\
\hline \multirow[t]{2}{*}{ Constant } & $2.021^{* * *}$ & -0.025 \\
\hline & $(0.393)$ & $(0.471)$ \\
\hline \multirow[t]{2}{*}{ Cooperative Professionalism } & $0.264^{* * *}$ & $0.625^{* * *}$ \\
\hline & $(0.080)$ & $(0.139)$ \\
\hline \multirow[t]{2}{*}{ Hierarchic Rigidity and Competition } & $-0.361^{* * *}$ & $-0.259^{* *}$ \\
\hline & $(0.064)$ & $(0.104)$ \\
\hline \multirow[t]{2}{*}{ Meritocratic Professionalism } & $0.341^{* * *}$ & $0.487^{* * *}$ \\
\hline & $(0.073)$ & $(0.123)$ \\
\hline \multirow[t]{2}{*}{ Company Age (ln) } & $0.141^{* * *}$ & -0.039 \\
\hline & $(0.048)$ & $(0.085)$ \\
\hline \multirow[t]{2}{*}{ Number of Employees (ln) } & 0.00002 & 0.037 \\
\hline & $(0.022)$ & $(0.031)$ \\
\hline \multirow[t]{2}{*}{ ISO 14000 (Dummy) } & $0.505^{* * *}$ & 0.141 \\
\hline & $(0.125)$ & $(0.202)$ \\
\hline Observations & 72 & 81 \\
\hline $\mathrm{R}^{2}$ & 0.769 & 0.626 \\
\hline Adjusted $\mathrm{R}^{2}$ & 0.748 & 0.596 \\
\hline Residual Std. Error & $0.362(\mathrm{df}=65)$ & $0.605(\mathrm{df}=74)$ \\
\hline F Statistic & $36.087^{* * *}(\mathrm{df}=6 ; 65)$ & $20.662^{* * *}(\mathrm{df}=6 ; 74)$ \\
\hline
\end{tabular}

Note. Table 2 shows how the effect of variables varies between correlational classes. ${ }^{*} \mathrm{p}<0.1$; ${ }^{* *} \mathrm{p}<0.05$; ${ }^{* * *} \mathrm{p}<0.01$; Chow test of structural change $(\mathrm{F}=2.322, \mathrm{p}=0.028)$. Standard error in parentheses. Dimensions of the scale of organizational values defined in the method section. Reactive and Resilient Classes are the groups resulting from the analysis of shared meaning schemes through the CCA. Each group refers to a different scheme. 
Table 2 shows the regression coefficients recorded for both classes, whereas Figure 5 presents the coefficients with the errors. The explanation coefficient was higher in the class of reactive schemas $\left(\mathrm{R}^{2}=0.769\right)$ and some coefficients presented differences in the class of resilient schemas. The effect of both professionalism types on the resilient class was stronger than that of hierarchical rigidity and competition. No other variable referring to the organization was significant in the class of resilient schemas, whereas company age $(b=0.141)$ and ISO $14000(b=0.505)$ were significant in the class of reactive schemas.

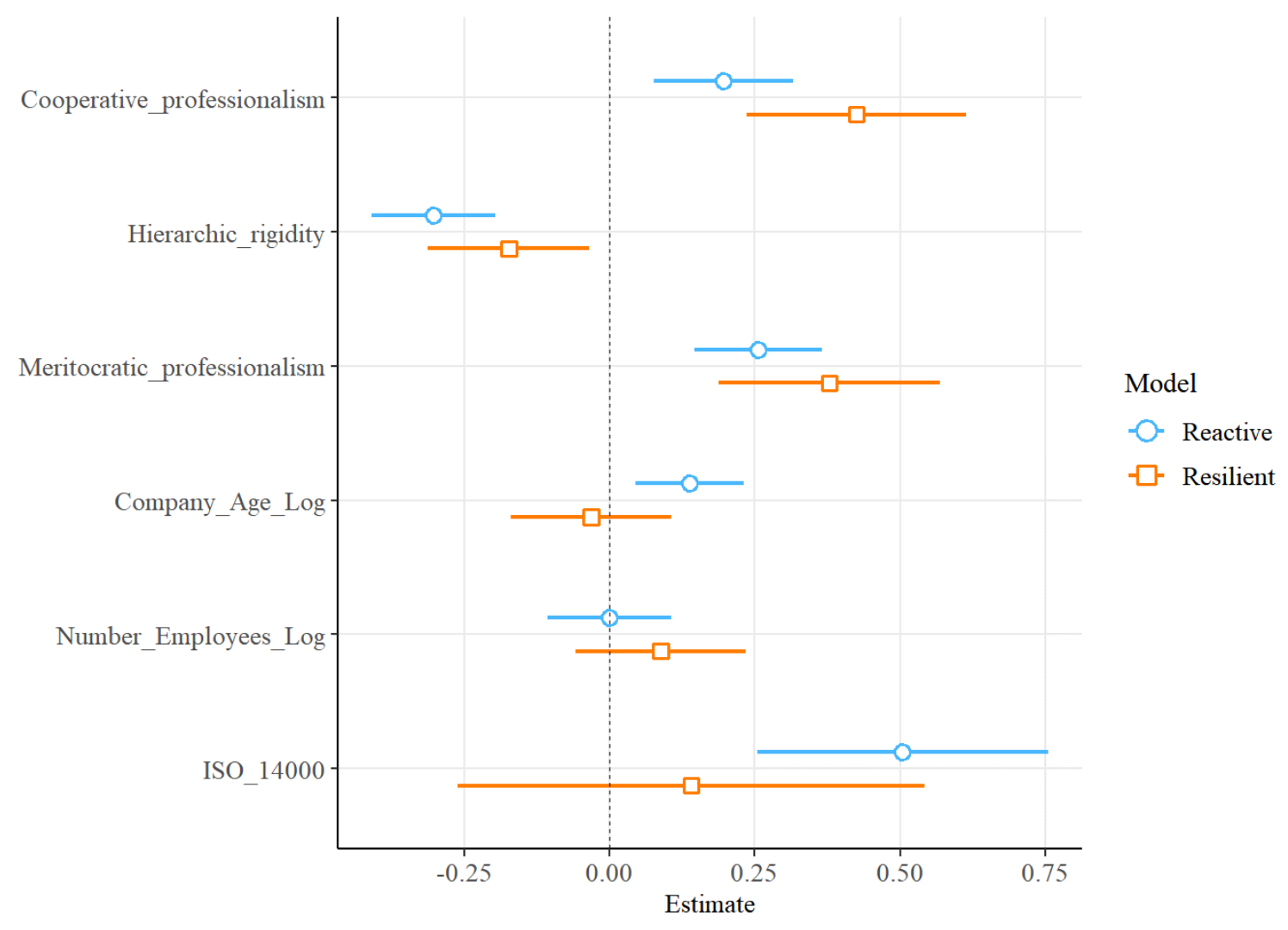

Figure 5. Coefficients and standard error of regression models.

Note. Figure 5 shows graphically how the effect of variables varies between correlational classes. Dependent variable: Employee Satisfaction and Appreciation. The dots represent the standardized coefficients of each variable generated in the OLS models. The lines refer to the confidence interval. Blue dots and lines refer to the effects in the reactive class. Orange dots and lines refer to the effects in the resilient class.

Each schema responds to the attitude toward employee appreciation and satisfaction in a different way. Based on the regression coefficients, although reactive schemas strongly react to exogenous aspects linked to the organization — such as rigidity, company age, and ISO 14000 - these factors are ignored or have less impact on resilient schemas, since endogenous factors, such as attitudes toward cooperative and meritocratic professionalism, have a greater effect on them. This fact was corroborated by the Chow structural change test (Table 2), according to which the two models were structurally different from each other $(p=0.047)$. Reactive schemas reverberated issues associated with the organization, whereas the resilient ones ignored them and focused on internal aspects such as attitude toward professionalism. As previously mentioned, since correlational classes are associated with different cognitive structures, they refer to different ways of appreciating organizational culture.

\section{DISCUSSION AND CONCLUSION}

Shared cultural schemas have gained prominence in studies about culture (Hunzaker \& Valentino, 2019) and brought sociology and cultural anthropology closer to the cognitive science field (Wood et al., 2018). Despite 
the importance of such concept, ways of measuring these schemas have always been challenging (Boutyline, 2017), since conventional methods were not capable of capturing them based on two cultural analysis principles, namely: relationality, whose meanings and attitudes do not emerge from entities in isolation, but from associations between them; and multiplicity, according to which respondents organize themselves into two, or more, groups based on simultaneous similarity and divergence patterns between attitudes (DiMaggio et al., 2018). These aspects have been particularly ignored in organizational studies, although studies available in the literature acknowledge that organizational culture manifests itself through shared schemas (Harris, 1994; Langfield-Smith, 1992; Miranda et al., 2015).

To fill these gaps, the present tutorial article aimed at introducing the analysis of correlational classes as a methodological alternative to map cultural schemas. It exemplified its use based on a survey conducted with 207 workers from different companies, which applied CCA based on organizational value scale adapted to the Brazilian context.

Two different classes were herein identified; they were called reactive and resilient schemas. Although they do not operate as predictor variables, they show different covariance structures between attitudes and allow revealing effects that would be ignored in the full sample (DiMaggio et al., 2018). Based on the herein adopted example, it was possible showing that each class has a different equifinality, i.e., different association paths between organizational variables and attitudes in the analysis of employee appreciation and satisfaction.

Based on CCA, the herein introduced method provided a quantitative way of capturing shared meanings that goes beyond the mere agreement between respondents ('consensus'), something that was already captured through cluster analysis. New hypotheses can be outlined in the management field, instead of being limited to the study of cultural schemas. Such methods can be used to assess consistency in immaterial elements such as cultures, values, tastes, and beliefs ('tightness'), but it can also be used to assess the effects of consistency

\section{REFERENCES}

Aktaş, E., Çiçek, I., \& Kıyak, M. (2011). The effect of organizational culture on organizational efficiency: The moderating role of organizational environment and CEO values. Procedia - Social and Behavioral Sciences, 24(2011), 1560-1573. https://doi.org/10.1016/j.sbspro.2011.09.092

Arditi, D., Nayak, S., \& Damci, A. (2017). Effect of organizational culture on delay in construction. International Journal of Project Management, 35(2),136-147. https://doi.org/10.1016/j.ijproman.2016.10.018 between material practices and organizational characteristics such as the adoption of practices associated with corporate governance, quality management, market analysis, and even analysis of strategic behavior of companies.

Although there are no limitations inherent to the use of CCA in the organizational context, two points are worth mentioning. First, as already mentioned by Boutyline (2017), since schematic similarity is captured employing Pearson's correlation between cases (rows), other measures of similarity more suitable for breaking linearity assumptions can be used. Second, CCA uses a method of maximizing modularity as a method of partitioning data. In some situations, for example, when there are very dense, very large, or small networks, the method has a resolution limit that can bias the results (Good, De Montjoye, \& Clauset, 2010). This leads to the search for alternative methods of partitioning, as well as alternative ways of testing cluster accuracy. In this study, we tested whether the method preserved the desired heterogeneity using Jennrich's test (1970).

It was possible concluding that correlational class analysis (CCA), which is an improved relational class analysis (RCA), uses a new way of analyzing data in the quantitative research field since it uses modularity algorithms in networks to evaluate relational patterns between cases, which go beyond the mere similarity of answers. Thus, if this method is useful to capture the multivocality of cultural schemas, it can also be useful to capture any class of systemic effect between cases, which refers to a huge field of investigation, whose instrument is described in detail in this tutorial article.

\section{ACKNOWLEDGMENTS}

The first author is deeply indebted to John Mohr (in memorian), who was a great supporter of the use of relational methods such as CCA. We also thank the two anonymous reviewers, who contributed to the improvement of the manuscript, as well as the journal's Associate Editor for Tutorial Articles and Open Data, Henrique Castro Martins.
Aßfalg, A., \& Erdfelder, E. (2012). CAML-Maximum likelihood consensus analysis. Behavior Research Methods, 44(1), 189 201. https://doi.org/10.3758/s13428-011-0138-0

Baldassarri, D., \& Goldberg, A. (2014). Neither ideologues nor agnostics: Alternative voters' belief system in an age of partisan politics. American Journal of Sociology, 120(1), 45-95. https://doi.org/10.1086/676042 
Bansal, P., \&Clelland, I. (2004). Talking trash:Legitimacy, impression management, and unsystematic risk in the context of the natural environment. Academy of Management Journal, 47(1), 93-103. https://doi.org/10.2307/20159562

Barbet, B. (2020). Nobody seems to be fully representing me: Differential inter-attitudinal cohesion systems and their effects on satisfaction with the political system. Electoral Studies, 64, 102116. https://doi.org/10.1016/j.electstud.2019.102116

Basov, N., \& Brennecke, J. (2017). Structure, content and meaning of organizational networks: Extending network thinking. Research in the Sociology of Organizations, 53, 87-112. https://doi.org/10.1108/S0733-558X20170000053005

Bourdieu, P. (1984). Distinction: A social critique of the judgement of taste. Cambridge: Harvard University Press.

Boutyline, A. (2017). Improving the measurement of shared cultural schemas with correlational class analysis: Theory and method. Sociological Science, 4(15), 353-393. https://doi.org/10.15195/v4.a15

Boutyline, A., \& Vaisey, S. (2017). Belief network analysis: A relational approach to understanding the structure of attitudes. American Journal of Sociology, 122(5), 13711447. https://doi.org/10.1086/691274

Calori, R. \& Sarnin, P. (1991). Corporate culture and economic performance: a French study. Organization Studies, 12(1), 49-74. https://doi.org/10.1177/017084069101200104

Corritore, M., Goldberg, A., \& Srivastava, S. (2020). Duality in diversity: How intrapersonal and interpersonal cultural heterogeneity relate to firm performance. Administrative Science Quarterly, 65(2), 359-394. https://doi.org/10.1177/0001839219844175

Daenekindt, S. (2017). On the structure of dispositions. Transposability of and oppositions between aesthetic dispositions. Poetics, 62, 43-52. https://doi.org/10.1016/j.poetic.2017.01.004

Daenekindt, S. (2019). Out of tune. How people understand social exclusion at concerts. Poetics, 74, 101341. https://doi.org/10.1016/j.poetic.2018.12.002

Daenekindt, S., Koster, W., \& Van der Waal, J. (2017). How people organise cultural attitudes: cultural belief systems and the populist radical right. West European Politics, 40(4), 791811. https://doi.org/10.1080/01402382.2016.1271970

DiMaggio, P. (1997). Culture and Cognition. Annual Review of Sociology, 23, 263-87. https://doi.org/10.1146/annurev.soc.23.1.263

DiMaggio, P., \& Goldberg, A. (2018). Searching for Homo economicus: Variation in Americans' construals of and attitudestoward markets. European JournalofSociology, 59(2), 151-189. https://doi.org/10.1017/S0003975617000558

DiMaggio, P., Sotoudeh, R., Goldberg, A., \& Shepherd, H. (2018). Culture out of attitudes: Relationality, population heterogeneity and attitudes toward science and religion in the US. Poetics, 68, 31-51. https://doi.org/10.1016/j.poetic.2017.11.001
Emirbayer, M. (1997). Manifesto for a Relational Sociology. American Journal of Sociology, 103(2), 281-317. https://doi.org/10.1086/231209

Ferreira, M., Assmar, E., Estol, K., Helena, M., \& Cisne, M. (2002). Desenvolvimento de um instrumento brasileiro para avaliação da cultura organizacional. Estudos de Psicologia, 7(2), 271-280. https://doi.org/10.1590/S1413-294X2002000200008

Garro, L. C. (2000). Remembering what one knows and the construction of the past: A comparison of cultural consensus theory and cultural schema theory. Ethos, 28(3), 275-319. https://doi.org/10.1525/eth.2000.28.3.275

Geisen, T., Hassler, B., Wagner, S., Buys, N., Randall, C., Harder, H., ... \& Scott, L. (2019). Raising Awareness and Appreciation: Employee Perspectives on Disability Management in Swiss Companies. International Journal of Disability Management, 14(2019), e1. https://doi.org/10.1017/idm.2019.1

Goldberg, A. (2011). Mapping shared understandings using relational class analysis: The case of the cultural omnivore reexamined. American Journal of Sociology, 116(5), $1397-$ 1436. https://doi.org/10.1086/657976

Good, B. H., De Montjoye, Y. A., \& Clauset, A. (2010). Performance of modularity maximization in practical contexts. Physical Review E, 81(4), 046106. https://doi.org/10.1103/PhysRevE.81.046106

Hair, J., Jr., Black, W., Babin, B., \& Anderson, R. (2018). Multivariate Data Analysis (8th ed.). Upper Saddle River: Prentice-Hall.

Harris, S. (1994). Organizational cultureand individual sensemaking: A schema-based perspective. Organization Science, 5(3), 309-321. https://doi.org/10.1287/orsc.5.3.309

Hofstede, G., Neuijen, B., Ohayv, D., \& Sanders, G. (1990). Measuring organizational cultures: A qualitative and quantitative study across twenty cases. Administrative Science Quarterly, 35(2), 286-316. https://doi.org/10.2307/2393392

Hunzaker, M., \& Valentino, L. (2019). Mapping cultural schemas: From theory to method. American SociologicalReview, 84(5), 950-981. https://doi.org/10.1177/0003122419875638

Jennrich, R. I. (1970). An asymptotic $\chi 2$ test for the equality of two correlation matrices. Journal of the American Statistical Association, 65(330), 904-912. https://doi.org/10.1080/01621459.1970.10481133

Knoll, M., Neves, P., Schyns, B., \& Meyer, B. (2020). A multilevel approach to direct and indirect relationships between organizational voice climate, team manager openness, implicit voice theories, and silence. Applied Psychology. $O(0), 1-37$. https://doi.org/10.1111/apps.12242

Langfield-Smith, K. (1992). Exploring the need for a shared cognitive map. Journal of Management Studies, 29(3), 349-368. https://doi.org/10.1111/j.1467-6486.1992.tb00669.x

MacQueen, J. (2020). The flow of organizational culture: New thinking and theory for better understanding and process. Bethel, AK: Palgrave Macmillan. https://doi.org/10.1007/978-3-030-25685-2 
Martin, J. L. (2000). The relation of aggregate statistics on beliefs to culture and cognition. Poetics, 28(1), 5-20. https://doi.org/10.1016/S0304-422X(00)00010-3

Martin, J. L. (2002). Power, authority, and the constraint of belief systems. American Journal of Sociology, 107(4), 861-904. https://doi.org/10.1086/343192

Miranda, S., Kim, I., \& Summers, J. D. (2015). Jamming with social media: How cognitive structuring of organizing vision facets affects IT innovation diffusion. MIS Quarterly, 39(3), 591-614. https://doi.org/10.25300/MISQ/2015/39.3.04

Mohr, J. \& White, H. (2008). How to Model an Institution. Theory and Society, 37, 485-512. https://doi.org/10.1007/s11186-008-9066-0

Netemeyer, R., Bearden, W., \& Sharma, S. (2003). Scaling procedures: Issues and applications. Thousand Oaks: Sage. https://doi.org/10.4135/9781412985772

Newman, M. E. (2006). Modularity and community structure in networks. Proceedings of The National Academy of Sciences, 103(23), 8577-8582. https://doi.org/10.1073/pnas.0601602103

Nunnaly, J. C. (1978). Psychometric Theory (2 ${ }^{\text {nd }}$ ed). New York, NY: McGraw-Hill.

Oberg, A., Korff, V., \& Powell, W. (2017). Culture and Connectivity Intertwined: Visualizing Organizational Fields as Relational Structures and Meaning Systems. Research in the Sociology of Organizations, 53, 17-47. https://doi.org/10.1108/S0733-558X20170000053001

Raines,S.(2003).Perceptionsoflegitimacyandefficacyininternational environmental management standards: The impact of the participation gap. Global Environmental Politics, 3(3), 4773. https://doi.org/10.1162/152638003322469277

\section{Authorship}

\section{Luciano Rossoni*}

Universidade do Grande Rio, Programa de Pós-graduação em Administração.

Rua da Lapa, no 86, Centro, 20021-170, Rio de Janeiro, RJ, Brazil.

E-mail address: 1rossoni@gmail.com

(1) https://orcid.org/0000-0003-2289-0879

\section{Clayton Pereira Gonçalves}

Universidade do Grande Rio, Programa de Pós-graduaçáo em Administração.

Rua da Lapa, no 86, Centro, 20021-170, Rio de Janeiro, RJ, Brazil.

E-mail address: crmiax@gmail.com

(1) https://orcid.org/0000-0001-9743-8057
Rawlings, C., \& Childress, C. (2019). Emergent Meanings: Reconciling Dispositional and Situational Accounts of Meaning-Making from Cultural Objects. American Journal of Sociology, 124(6), 1763-1809. https://doi.org/10.1086/703203

Reisyan, G. (2016). Neuro-organizational culture: A new approach to understanding human behavior and interaction in the workplace. Cologne: Springer. https://doi.org/10.1007/978-3-319-22147-2

Rofcanin, Y., Las Heras, M., \& Bakker, A. B. (2017). Family supportive supervisor behaviors and organizational culture: Effects on work engagement and performance. Journal of Occupational Health Psychology, 22(2), 207-217. https://doi.org/10.1037/ocp0000036

Romney, A. K., Weller, S. C., \& Batchelder, W. H. (1986). Culture as consensus: A theory of culture and informant accuracy. American Anthropologist, 88(2), 313-338. https://doi.org/10.1525/aa.1986.88.2.02a00020

Schein, E. (1992). Organizational culture and leadership. San Francisco: Jossey-Bass.

Smircich, L. (1983). Concepts of Culture and Organizational Analysis. Administrative Science Quarterly, 28(3), 339358. https://doi.org/10.2307/2392246

Strauss, C. \& Quinn, N. (1997). A cognitive theory of cultural meaning. Cambridge: Cambridge University Press. https://doi.org/10.1017/CBO9781139167000

Wood, M. L., Stoltz, D. S., Van Ness, J., \& Taylor, M. A. (2018). Schemas and frames. Sociological Theory, 36(3), 244-261. https://doi.org/10.1177/0735275118794981

Wu, A. (2014). Ideological polarization over a China-as-superpower mindset: An exploratory charting of belief systems among Chinese Internet users, 2008-2011. International Journal of Communication, 8(2014), 2650-2679. Retrieved from https://ijoc.org/index.php/ijoc/article/view/2346/1212

Zerubavel, E. (1997). Social Mindscapes: An Invitation to Cognitive Sociology. Cambridge: Harvard University Press.

\section{Mônica Pereira da Silva}

Universidade do Grande Rio, Programa de Pós-graduação em Administração.

Rua da Lapa, no 86, Centro, 20021-170, Rio de Janeiro, RJ, Brazil.

E-mail address: monicapsilva8@hotmail.com

(D) https://orcid.org/0000-0001-6391-860X

\section{Alex Ferreira Gonçalves}

Universidade do Grande Rio, Programa de Pós-graduação em Administração.

Rua da Lapa, no 86, Centro, 20021-170, Rio de Janeiro, RJ, Brazil.

E-mail address: afgoncalves1979@gmail.com

(1) https://orcid.org/0000-0003-4161-6170

* Corresponding Author 


\section{Authors' Contributions}

$1^{\text {st }}$ author: conceptualization (lead); data curation (lead); formal analysis (equal); funding acquisition (lead); investigation (lead); methodology (lead); project administration (lead); resources (lead); software (supporting); supervision (lead); validation (lead); visualization (supporting); writing-original draft (lead).

$2^{\text {nd }}$ author: data curation (equal); formal analysis (equal); investigation (equal); methodology (equal); software (lead); visualization (lead); writing-original draft (supporting); writing-review \& editing (supporting).

$3^{\text {rd }}$ author: formal analysis (equal); validation (supporting); writing-original draft (equal); writing-review \& editing (supporting).

$4^{\text {th }}$ author: formal analysis (equal); validation (supporting); writing-original draft (equal); writing-review \& editing (supporting).

\section{Funding}

The authors would like to thank CNPq (Process 435946 / 2018-8) and FAPERJ (Process E-26 / 203.238 / 2017) for the financial resources.

\section{Conflict of Interests}

The authors have stated that there is no conflict of interest.

\section{Copyrights}

RAC owns the copyright to this content.

\section{Plagiarism Check}

The RAC maintains the practice of submitting all documents approved for publication to the plagiarism check, using specific tools, e.g.: iThenticate.

\section{Peer Review Method}

This content was evaluated using the double-blind peer review process. The disclosure of the reviewers' information on the first page is made only after concluding the evaluation process, and with the voluntary consent of the respective reviewers.

\section{Data Availability}

All data and materials were made publicly available through the Harvard Dataverse platform and can be accessed at:

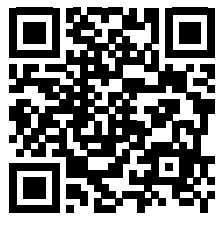

Rossoni, L., Gonçalves, C. P., Silva, M. P. da, \& Gonçalves, A. F. (2020). Replication data for: Mapping organizational culture schemas based on correlational class analysis: A tutorial. Harvard Dataverse, v1. https://doi.org/10.7910/DVN/UHZFBO 


\section{APPENDIX I — SAMPLES HETEROGENEITY BETWEEN CORRELATIONAL CLASSES}
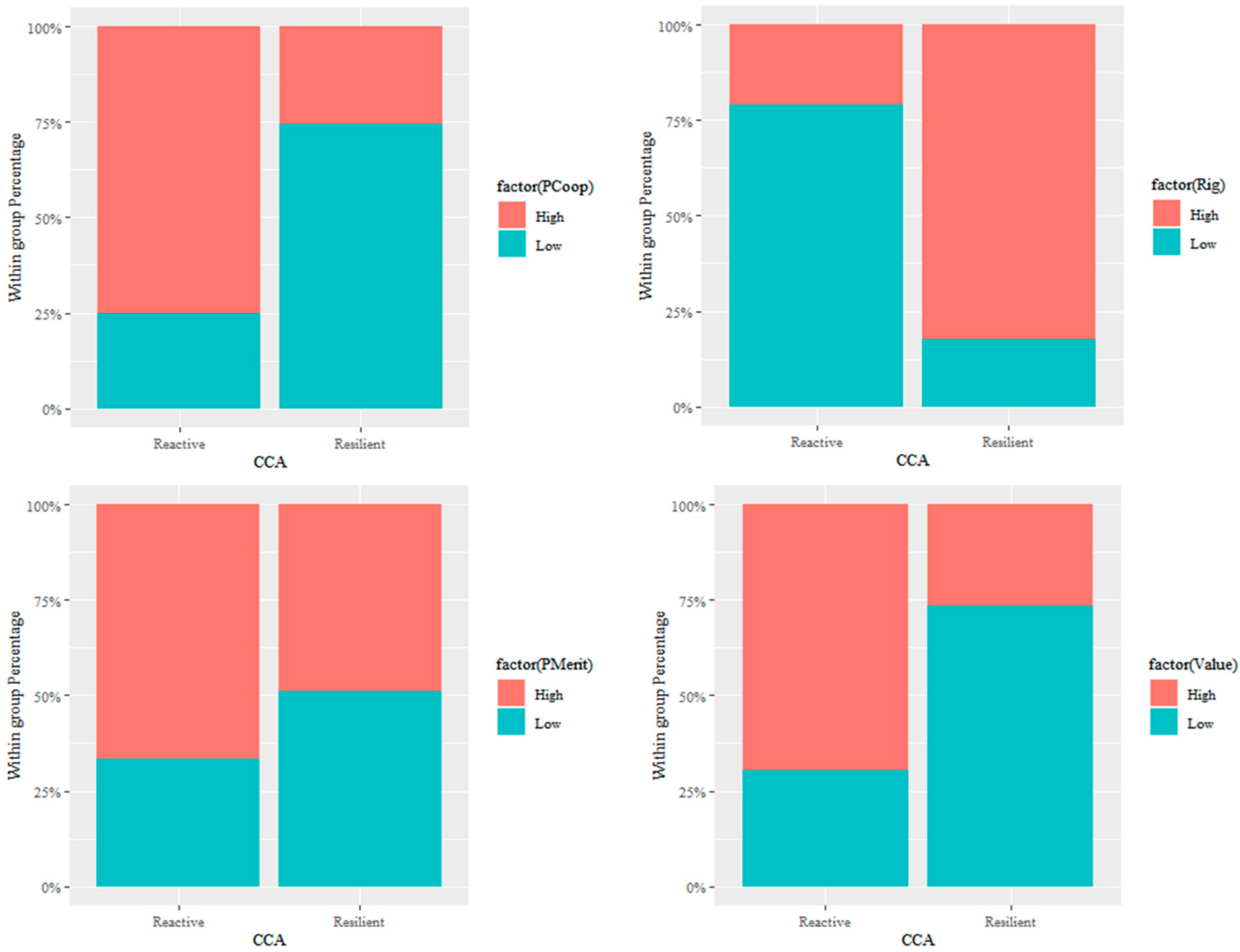

Figure A1. Crossing homogeneous groups and correlational classes.

Boutyline (2017) points out that the schematic classes must present a significant degree of heterogeneity in the item's responses used in their construction. We demonstrate this heterogeneity by breaking each dimension of the organizational values scale into two groups: one with response values above the median (High), represented by the red color; and another with values below the median (Low), in greenish tone. All schematic classes have a significant degree of heterogeneity in responses, although the groups vary in frequency. 